\title{
AVALIAÇÃO FORMATIVA, MEDIADORA E INTEGRAL: UMA PROPOSTA DO PROGRAMA PALAVRA DE CRIANÇA
}

Integral, mediative and forming evaluation: a proposal by child's word program

\author{
FRANCISCO MARCOS PEREIRA SOARES ${ }^{1}$ \\ RAIMUNDA ALVES MELO ${ }^{2}$ \\ ANTÔNIA FLAVIA MORAES DA COSTA ${ }^{3}$
}

\begin{abstract}
RESUMO: O estudo em referência discute a avaliação da aprendizagem proposta pelo Programa Palavra de Criança, desenvolvido por 77 (setenta e sete) municípios do Piauí. Para efeito desta investigação, pesquisamos o Caderno de Aprendizagem como instrumento de avaliação, que permite o registro e acompanhamento da aprendizagem dos alunos. O estudo encontra-se fundamentado pelos autores Hoffmann (2005/2012), Fernandes (2002), Luckesi (2005), dentre outros. O direcionamento metodológico inclui-se na vertente da pesquisa qualitativa, tendo como referencial teórico Chizzotti (2006/1991) e Gil (2002/2011). A produção dos dados foi realizada mediante a aplicação de questionários com duas professoras que trabalharam com a proposta do Programa. Também realizou-se observação em duas turmas do ciclo da alfabetização. A análise de conteúdo dos questionários e os dados observacionais revelam que o Caderno de Aprendizagem é um instrumento de avaliação no qual os estudantes trabalham com suas dúvidas e possibilidades de avanço, facilitando a prática de uma avaliação formativa e de estudos paralelos, podendo ser uma iniciativa do próprio estudante ou uma prática a ser incorporada pelo professor em seu planejamento.
\end{abstract}

Palavras-chave: Avaliação. Educação Infantil. Portfólios.

\begin{abstract}
The study in reference discusses the assessment of learning proposed by the Word of Child Program, developed by 77 (seventy-seven) municipalities of Piaui. For purposes of this research, we studied the Learning Notebook as evaluation instrument, which allows the recording and monitoring of student learning. The study is based by the authors Hoffmann (2005/2012), Fernandes (2002), Luckesi (2005), among others. The methodology includes guidance on the aspect of qualitative research, the theoretical reference Chizzotti (2006/1991) and Gil (2002/2011). The production of data was performed by applying questionnaires with two teachers who worked with the proposal of the program. Also held observation in two literacy cycle classes. The questionnaires content analysis and observational data reveal that the Learning Notebook is an assessment tool in which students work with their doubts and advancement opportunities, facilitating the practice of formative assessment and parallel studies, may be an initiative the student himself or practice to be incorporated by the teacher in his planning.
\end{abstract}

Keywords: Evaluation. Child education. Portfolios.

\section{INTRODUÇÃO}

\footnotetext{
${ }^{1}$ Especialista em Gestão Educacional em espaços escolares e não escolares pela UESPI.

${ }^{2}$ Mestre em educação pela UFPI e professora do programa de educação de campo da UFPI.

${ }^{3}$ Mestre em educação pela UFPI
} 
O presente estudo objetiva discutir o processo de avaliação da aprendizagem, proposto pelo Programa Palavra de Criança. Para tanto, apropriamo-nos da história da Professora Marta, uma vez que ela contém importantes reflexões que nos ajuda a entender melhor as funções e instrumentos que compõem a proposta avaliativa do referido Programa, a saber: avaliação formativa, mediadora e integral e o Caderno de Aprendizagem, enquanto instrumento avaliativo. Vejamos então, a referida situação ${ }^{4}$ :

Conta uma história que Professora Marta, no seu primeiro dia de aula, parou em frente aos seus alunos do $5^{\circ}$ ano do ensino fundamental e, como todos os demais professores, lhes disse que gostava de todos por igual. No entanto, ela sabia que isso era quase impossível, já que no fundo da sala estava sentado um garoto chamado Víctor. A professora havia observado que ele não se dava bem com os colegas de classe, não fazia as tarefas de casa e não participava das aulas. Houve até momentos em que ela sentia prazer em lhe dar notas vermelhas ao corrigir suas provas e trabalhos.

Ao iniciar o ano letivo, era solicitado a cada professor que lesse, com atenção, o Caderno de Aprendizagem para tomar conhecimento das anotações feitas por eles, sobre o desempenho das crianças, com vista o planejamento de situações de aprendizagem, sobre como as crianças se relacionavam com os colegas, seus modos de ser, suas atitudes, suas responsabilidades e algumas questões de ordem familiar que pudessem interferir na aprendizagem escolar. A Professora Marta deixou os registros que falavam de Víctor por último. Mas quando leu foi grande sua surpresa.

A professora do primeiro ano do ensino fundamental havia anotado o seguinte: Víctor é um menino brilhante e simpático. Seus trabalhos sempre estão em ordem e muito organizados, está aprendendo a ler e escrever. Faz todas as tarefas escolares e os exercícios que leva para casa. É muito participativo durante as aulas. Tem bons modos e é muito agradável estar perto dele. A professora do segundo ano escreveu: Víctor é um aluno excelente e muito querido pelos seus colegas. Já sabe ler e escreve com autonomia. Produz excelentes textos. Adora estudar Ciências e diz que quando crescer quer ser médico, mas tem estado triste e preocupado com a sua mãe que está com uma doença grave e desenganada pelos médicos. A vida em família deve estar muito difícil.

Da professora do terceiro ano constava a seguinte anotação: a morte de sua mãe foi um golpe muito duro para Víctor. Ele procura fazer o melhor, mas não responde mais as atividades de casa. Também tem manifestado pouco interesse pela leitura e escrita de textos. Não fala mais sobre o sonho de ser médico. Parece-me que seu pai não tem tido tempo ou interesse pelos seus estudos. Tenho medo que sua vida seja prejudicada se ninguém tomar providências para ajudá-lo. A professora do quarto ano escreveu: Víctor anda muito distraído e não mostra interesse algum pelos estudos. As vezes expressa revolta por ter perdido a mãe muito cedo. Não participa das aulas. Apresenta baixo desempenho principalmente nas disciplinas de Língua Portuguesa e Ciências. Tem poucos amigos e muitas vezes, dorme na sala de aula. Com estas notas mal vai conseguir passar de ano.

A Professora Marta se deu conta do problema e ficou terrivelmente envergonhada. Sentiu-se ainda pior quando lembrou dos presentes que os alunos lhe haviam dado, envoltos em papéis coloridos, exceto o de Víctor, que estava enrolado num papel marrom de supermercado. Lembrou-se de que abriu o pacote com tristeza, enquanto os outros garotos riam ao ver uma pulseira faltando algumas pedras e um vidro de perfume pela metade. Apesar das piadas, ela disse que o presente era precioso e pôs a pulseira no braço e um pouco do perfume sobre a mão. Naquela ocasião, Víctor ficou um pouco mais tempo na escola do que o de costume. Lembrou-se ainda, que ele lhe

\footnotetext{
1 Autor desconhecido. Reelaborada a partir da história original que se encontra no endereço eletrônico: < http://www.psicologiapravoce.com.br/metafora.asp?nr=721 >. Acesso em: 25 jul. 2016.
} 
disse que ela estava cheirosa como a mãe. Naquele dia, depois que todos se foram, a Professora Marta chorou por longo tempo... Em seguida, decidiu mudar sua maneira de ensinar e passou a dar mais atenção aos seus alunos, especialmente ao Víctor.

Passou a analisar melhor os seus registros e a apoiá-lo em suas dificuldades. Com o passar do tempo ela notou que o garoto só melhorava, e quando mais ela lhe dava carinho e atenção, mais ele se animava. Ao finalizar o ano letivo, Víctor se destacou como um dos melhores alunos da classe. Um ano mais tarde ela recebeu um cartão de natal em que Víctor lhe dizia que era a melhor professora que teve na vida. Seis anos depois, recebeu uma carta de Víctor, contando que havia concluído o ensino médio e que ela continuava sendo a melhor professora que tivera. As notícias se repetiram até que um dia ela recebeu uma carta assinada pelo Médico: Dr. Victorio de Almeida Campo, seu antigo aluno, mais conhecido como Víctor.

Mas a história não terminou aqui. A Professora Marta recebeu outra carta, em que Víctor a convidava para ser madrinha de seu casamento. Ela aceitou o convite e no dia do casamento estava usando a pulseira que ganhou dele anos antes. Quando os dois se encontraram, abraçaram-se por longo tempo e Víctor lhe disse ao ouvido: obrigado por acreditar em mim e me fazer sentir importante, demonstrando-me que posso fazer a diferença. Mas ela, com os olhos banhados em lágrimas sussurrou baixinho: Você está enganado! Foi você que me ensinou que eu podia fazer a diferença, afinal eu não sabia ensinar até que o conheci.

O fato é que a história da Professora Marta nos possibilita refletir sobre os múltiplos desafios que envolvem a avaliação da aprendizagem, colaborando para um melhor entendimento da mesma, sobre a complexidade do ato de avaliar e o papel dos instrumentos e registros, neste processo,

Segundo Hoffmann (2005), avaliação da aprendizagem é um conjunto de procedimentos didáticos que se estendem por um longo tempo e se dão em vários espaços escolares, de caráter múltiplo, complexo tal como se delineia um processo. Para a autora:

Decorre daí que não se deve denominar por avaliação testes, provas ou exercícios, cadernos de aprendizagem (instrumentos de avaliação). Muito menos se deve nomear por avaliação boletins, fichas, relatórios, fichas de acompanhamento de expectativas de aprendizagem (registros de avaliação). (HOFFMANN, 2005, p. 13)

Dessa forma, quando tratamos sobre avaliação formativa, mediadora e integral estamos nos referindo a avaliação segundo sua função. Quando discutimos sobre o Caderno de Aprendizagem nos reportamos a um instrumento de avaliação. E quando mencionamos instrumentais de acompanhamento das expectativas de aprendizagem, nos referimos aos registros de avaliação. Desse modo, considerando estes esclarecimentos iniciais, conceituamos a seguir a avaliação, segundo a sua função.

\section{DAS CONCEPÇÕES DE AVALIAÇÃO NO PROCESSO DE ENSINO E APRENDIZAGEM}


O modo como o professor desenvolve as práticas pedagógicas de ensino e aprendizagem em sala de aula, relaciona-se diretamente com a concepção de avaliação por ele empreendida. Nesse sentido, é importante, mencionarmos três dessas concepções, conforme a leitura de alguns aportes teóricos, situados abaixo:

AVALIAÇÃO FORMATIVA: Conjunto de procedimentos didáticos que tem as funções de controle, porque assegura o cumprimento das etapas e dos procedimentos previstos no processo, a nível de professores e de alunos, evitando desvios do que foi planificado e caminhos distintos do determinado. Tem também a função de diagnóstico, quando se identificam os pré-requisitos dos alunos, situando-os relativamente aos objetivos definidos e regular os caminhos da aprendizagem, perante o que se pretende ensinar e se deseja que aprendam. (FERNANDES, 2002, p. 35)

AVALIAÇÃO MEDIADORA: Conjunto de procedimentos didáticos que se estendem por um longo tempo e em vários espaços escolares, de caráter processual e visando, sempre, à melhoria do objeto avaliado. Acompanhamento de um percurso de vida da criança, durante o qual ocorrem mudanças em múltiplas dimensões com a intenção de favorecer o máximo possível seu desenvolvimento. Acompanhar, em avaliação mediadora, é permanecer atento a cada criança, pensando em suas ações e reações, "sentindo", percebendo seus diferentes jeitos de ser e de aprender. (HOFFMANN, 2012, p. 12-14)

AVALIAÇÃO INTEGRAL: Conjunto de procedimentos didáticos trabalhados em variados tempos e espaços de aprendizagem, incluindo o acompanhamento das aprendizagens dos alunos na sua completude, realizada por meio de procedimentos e instrumentos que avaliam a criança como ser completo, indivisível e social, em práticas que dialogam e se articulam para acompanhá-la de forma integral em seus aspectos físicos, emocionais, afetivos, cognitivos e sociais. (PROGRAMA PALAVRA DE CRIANÇA, 2015, p. 13)

Os conceitos apresentados por Fernandes (2002) caracterizam os procedimentos de avaliação formativa, cujo propósito visa informar o professor e o estudante sobre o momento inicial, os progressos obtidos ao longo do processo e localizar falhas com vistas a sua correção. Hoffmann (2012) discute os procedimentos de avaliação mediadora que envolve observar o aprendiz, analisar e compreender as estratégias de aprendizagem e tomar decisões pedagógicas favoráveis à aprendizagem dos educandos. O Programa Palavra de Criança (2015) apresenta sua concepção de avaliação integral que abrange o acompanhamento dos aspectos físicos, emocionais, afetivos, cognitivos e sociais.

A prática avaliativa orientada pela escola em que trabalhava a Professora Marta, a exemplo do que propõe o Programa Palavra de Criança, compunha-se de procedimentos de avaliação formativa, mediadora e integral, pois:

Os docentes eram orientados a tomar conhecimento das anotações feitas pelos outros professores nos anos anteriores, sobre o desempenho das crianças nas disciplinas, com vista o 
planejamento de situações de aprendizagem e a atenção individualizada, como propõe a avaliação formativa e mediadora.

Os docentes eram norteados a conhecerem como as crianças se relacionavam com os colegas, seus modos de ser, suas atitudes, suas responsabilidades e algumas questões de ordem familiar que pudessem interferir na aprendizagem das crianças, questões que se aproximam de uma avaliação integral.

Já o Caderno de Aprendizagem, a exemplo do que observamos na história da Professora Marta, nos permite obter informações sobre a história de vida das crianças, seus percursos de vida, seus processos de aprendizagem, como ocorreu com Victor, cuja infância foi marcada por acontecimentos que interferiram em sua vida familiar e em seu desempenho como estudante.

Vejamos como a sequência de informações que constam no Caderno de Aprendizagem, relatando aspectos referentes à aprendizagem, o comportamento, a responsabilidade com os estudos e a vida familiar de Victor, contribuem para uma melhor compreensão, tanto de seus avanços e expectativas de vida, como também dos problemas, que embora não sendo de ordem escolar, mas familiar, acabaram interferindo em sua vida pessoal e em sua aprendizagem, notadamente.

Contudo, devemos ressaltar que em um primeiro momento o sentimento da Professora Marta em relação à Víctor foi de julgamento e desprezo, e não de acolhimento e amorosidade: " $A$ professora havia observado que ele não se dava bem com os colegas de classe, não faria as tarefas de casa e não participava das aulas. Houve até momentos em que ela sentia prazer em lhe dar notas vermelhas ao corrigir suas provas e trabalhos". As reflexões que geraram mudanças no modo de agir da professora com o seu aluno Victor, surgiram a partir da leitura do Caderno de Aprendizagem, que lhe permitiu conhecer a história de vida da criança e se envolver emocionalmente com ela, como ilustramos a seguir: "A Professora Marta se deu conta do problema e ficon terrivelmente envergonhada. [...] Naquele dia, depois que todos se foram, [...] chorou por longo tempo.... Em seguida, decidiu- se a mudar sua maneira de ensinar e passon a dar mais atenção aos seus alunos, especialmente ao Victor". Esse episódio nos mostra a importância do registro como um mecanismo de estímulo à reflexão docente e consequentemente de mudança de concepção.

Desse modo, entendemos que o Caderno de Aprendizagem é um instrumento de avaliação que permite aos professores conhecerem o percurso de aprendizagem das crianças ao longo do ano e de anos subsequentes, a se sensibilizarem com suas histórias, bem como identificar entraves que interferem na aprendizagem para, a partir disso, planejar intervenções, com vista à garantia de seu sucesso escolar. Possibilita também, uma auto-reflexão sobre a prática docente. 
Segundo Brasil (2007), o Caderno de Aprendizagem é um instrumento no qual os estudantes se depararão com suas dúvidas e possibilidades de avanço, facilitando a prática de uma avaliação formativa e de estudos paralelos. Pode ser uma iniciativa do próprio estudante ou uma prática a ser incorporada pelo professor em seu planejamento. Esse Caderno pode ser utilizado em duas situações:

Atividades de acompanhamento dos conteúdos escolares com o propósito de superar as dificuldades e dúvidas que tenham ficado dos conteúdos já estudados nas aulas. Podem ser atividades de áreas variadas, bem como de apenas uma área. Essa prática pode orientar uma maior reflexão quanto ao conteúdo estudado e quanto às aprendizagens que o estudante vem realizando. Os registros reflexivos que têm por objetivo servir de auto avaliação para os estudantes. Podem ser registrados os caminhos que o estudante fez para sanar suas dúvidas, para compreender aquilo que ainda não sabia e agora já sabe, as dúvidas que ainda permanecem. (BRASIL, 2007, p. 33)

Nessa perspectiva, Luckesi (2005) afirma que o ato de avaliar deve estar a serviço da obtenção do melhor resultado possível, implica na disposição do professor em acolher a realidade como ela é, seja satisfatória ou insatisfatória, "o ato de avaliar é aquele que acolhe a situação, na sua verdade (como ela é)". A história da Professora Marta nos mostra como o acolhimento e a amorosidade são importantes na prática docente e nos processos avaliativos dos educandos.

Intervenções simples, como conhecer melhor as crianças, suas dificuldades, incentivá-las e acompanhá-las mais de perto, podem proporcionar melhorias importante na aprendizagem, como ilustra a história: "Passou a analisar melhor os seus registros e a apoiá-lo em suas dificuldades. Com o passar do tempo ela notou que o garoto só melhorava, e quando mais ela lhe dava carinho e atenção, mais ele se animava. Assim, tanto os registros feitos pelas crianças, evidenciando seus avanços e dificuldades, quanto os registros feitos pelos professores, sobre os progressos e dificuldades no processo de ensino e aprendizagem, sobre a relação que as crianças estabelecem consigo mesmo e com os colegas, as responsabilidades com os estudos, suas histórias de vida, possibilitam uma avaliação de caráter formativo, mediador e integral, que contribui para a proposição de encaminhamentos com vista à garantia da aprendizagem e sucesso na vida.

Os procedimentos de avaliação utilizados pela Professora Marta contemplam quatro princípios propostos pelo Programa Palavra de Criança: o princípio da individualização, que refere-se aos procedimentos relacionados a observação e cuidado com cada criança e de um tempo maior para aquela que precisa de mais apoio. O princípio da mediação, que se relaciona ao desenvolvimento de estratégias pedagógicas desafiadoras para que as crianças evoluam em todas as áreas do conhecimento (HOFFMANN, 2012). O principio da amorosidade, caracterizado pelo acolhimento e responsabilidade social do docente e o princípio da integralidade, em que os processos 
avaliativos não se limitam em apenas trabalhar/avaliar os aspectos cognitivos, mas também as capacidades físicas, sócio afetivas e emocionais, entre outras.

Essa proposta de avaliação do Programa Palavra de Criança não tem como pressuposto a punição, a premiação, o foco na memorização de conteúdos e somente a aprovação escolar, mas leva em consideração que as crianças possuem ritmos e processos de aprendizagem diferentes umas das outras, que precisam ser acolhidas em suas necessidades educativas, para que possam aprender verdadeiramente e que necessitam ser educadas/avaliadas de forma integral em seus aspectos físicos, emocionais, afetivos, cognitivos e sociais.

Trata-se de uma proposta que engloba, necessariamente a intervenção e amorosidade pedagógica, seja por meio do planejamento de atividades e práticas pedagógicas acolhedoras e inclusivas que favoreçam a aprendizagem das crianças, seja por meio da redefinição de posturas, da reorganização do ambiente de aprendizagem, da seleção de materiais, de modo que é necessário também, a adoção de instrumentos que favoreçam o processo de acompanhamento integral das crianças, como é o caso do Caderno de Aprendizagem.

Sobre o uso de instrumentos de registro, que certamente inclui tanto o Caderno de Aprendizagem, Hoffmann (2012, p. 117-118) registra que:

A questão principal, contudo, não está na nomenclatura utilizada, mas no que se compreende sobre esse instrumento. Ao relatar, documentar, o seu entendimento sobre o processo vivido pela criança, o professor deve se perceber participe desse processo, corresponsável pela história construída por ela, atribuindo, assim, significado pedagógico ao que relata e à amostra da produção que reúne no sentido de serem representativos do acompanhamento feito.

Considerando o exposto, o Programa Palavra de Criança orienta que os cadernos sejam utilizados não apenas como amostra dos trabalhos, mas principalmente, como procedimentos avaliativos que favorecem a observação docente, a reflexão sobre a prática, a ordenação e seleção de trabalhos significativos do ponto de vista da aprendizagem das crianças, cujos registros sejam capazes de subsidiar o planejamento de intervenções e o acolhimento das situações que neles forem expressas, com vistas a uma formação integral.

O Caderno de Aprendizagem possibilita que elas sejam participantes ativos na avaliação da aprendizagem, selecionando as melhores amostras de seu trabalho para incluí-las no Caderno, organizando vários tipos de atividades e registros que evidenciam suas aprendizagens e dificuldades, permitindo que a professora, a escola, as próprias crianças e suas famílias possam acompanhar o processo evolutivo. Deve garantir também o desenvolvimento reflexivo delas; o estímulo à originalidade, a criatividade e a autoavaliação. 
A estrutura desse Caderno incluiu uma capa, folha de apresentação da proposta, espaço para foto ou autorretrato da criança, quadro de informações importantes sobre a criança, mensagem para as famílias, relação das atividades selecionadas e que melhor representam o desempenho das crianças, instrumental de acompanhamento das expectativas de aprendizagem, coletânea das atividades e espaços para a família e a criança se pronunciarem, entre outros.

Contudo, devemos reforçar que ao apoiar as crianças na seleção de atividades que ilustrem o seu percurso de aprendizagem, temos que pensar na sua organização, pois este se torna significativo pelas intenções de quem o organiza. Não há sentido em orientar e sugerir a coleta dos trabalhos das crianças para mostrá-los aos gestores, coordenadores e pais somente como instrumento burocrático. Esse instrumento precisa se constituir em um conjunto de dados que expresse avanços, mudanças conceituais, novas formas de pensar e de fazer, referentes ao progresso educativo dos pequeninos.

Tanto o Caderno de Aprendizagem apresentam várias possibilidades de avaliação formativa, mediadora e integral, entre elas:

Beneficia qualquer tipo de educando, pois possibilita a apresentação em diferentes linguagens (escrita, desenhos, recortes, colagem, ilustrações, entre outras), favorecendo a valorização da identidade, pois ao construí-lo as crianças não se mostram apenas como estudantes, mas como sujeitos dispostos a aprender (sua história de vida, suas experiências são conhecidas e valorizadas).

As crianças percebem que o trabalho escolar lhe pertence; portanto, cabe-lhe assumir responsabilidades pela sua execução. Dessa forma, sentem-se motivadas a buscar formas diferentes de aprender, pois suas produções revelam suas capacidades e potencialidades, as quais poderão ser apreciadas por várias pessoas.

Permite que pais acompanhem detalhadamente o trabalho de seus filhos na escola, melhorando a relação família e escola e famílias e crianças e que os professores do ano seguinte tenham conhecimento do que cada criança já aprendeu e quais suas capacidades.

Sobre a periodicidade dos registros, o Programa Palavra de Criança orienta que sejam feitos diariamente por meio de atividades realizadas em sala de aula, possibilitando aos professores um retrato dos passos percorridos no desenvolvimento da aprendizagem. Segundo Cardoso (2012), essa forma de registrar diariamente a caminhada das crianças tem o objetivo de mostrar a importância de cada aula, de cada passo, como uma situação de aprendizagem e desenvolvimento.

É importante ressaltar que, ao propor uma situação de aprendizagem, ou o registro de uma atividade, o professor esteja atento a auxiliar as crianças no processo de construção do 
conhecimento escolar, fortalecendo a autoestima, permitindo que elas acompanhem suas conquistas, suas dificuldades e suas possibilidades ao longo do processo de aprendizagem. Os registros podem revelar o processo evolutivo das crianças em termos de suas linguagens expressivas em artes, na produção de escritas espontâneas, na descoberta e manipulação de materiais, na vivência de jogos simbólicos, na oralidade, no desenvolvimento motor (HOFFMANN, 2012).

Partindo deste princípio, o Programa definiu instrumentais de acompanhamento das expectativas de aprendizagem que são fixados no Caderno de Aprendizagem, contemplando aspectos da educação integral. Na Educação Infantil, compõem-se dos seguintes eixos: (Identidade e autonomia, Movimento, Músicas, Artes Visuais, Linguagem Oral e Escrita, Natureza e Sociedade e Matemática). No Ensino Fundamental $\left(1^{\circ}, 2^{\circ}\right.$ e $3^{\circ}$ ano), contemplam os eixos das capacidades: cognitivas (conhecimentos nas áreas de Língua Portuguesa, Matemática, História, Geografia, Ciências e Artes), físicas, éticas, estéticas e sócio afetivas, conforme detalhamento a seguir:

Capacidades de ordem física - estão associadas ao conhecimento e desenvolvimento das potencialidades corporais, ao autoconhecimento, ao uso do corpo na sua expressão das emoções, ao deslocamento com segurança.

Capacidades sócio afetivas - estão associadas à construção da autoestima, às atitudes no convívio social, à compreensão de si mesmo e dos outros, à possibilidade do estabelecimentos de condições para o convívio social, de modo que cada criança perceba-se como membro participante de um grupo de uma comunidade e de uma sociedade. Isso implica aprender a conviver com as diferenças de temperamento, de intensões, de hábitos e costumes, de cultura.

Capacidades de ordem ética e estética - estão associadas à possibilidade de construção de valores que norteiam a ação das crianças e as capacidades de produção artística e apreciação desta produção oriunda de diferentes culturas.

Capacidades de ordem cognitivas - estão associadas ao desenvolvimento dos recursos para pensar, o uso e apropriação de formas de representação e comunicação envolvendo resolução de problemas. Reorganizamos essas capacidades em expectativas de aprendizagem das seguintes áreas do saber: Língua Portuguesa, Matemática, Ciências, Geografia e História. (RCNEI, 1998, p. 48)

As expectativas de aprendizagem referem-se às capacidades que são almejadas para as crianças de 4 a 8 anos em seus aspectos físicos, sócio afetivos, éticos, estéticos cognitivos para mobilizarem suas habilidades motoras (saber fazer), seus conhecimentos (saber) e suas atitudes (saber ser) para solucionar problemas relacionados a aprendizagem e a vida cotidiana.

De acordo com a proposta, os instrumentais devem ser preenchidos a cada bimestre, a partir das observações feitas pelo professor, dos registros constantes nas atividades coletadas e registradas nos cadernos, de acordo com a seguinte legenda: amarelo para as capacidades, cujo 
desenvolvimento foi iniciado, azul para capacidades em aprofundamento e verde para capacidades consolidadas, conforme proposta em anexo no livro.

$\mathrm{Na}$ verdade, trata-se de uma proposta avaliativa fundamentada nas concepções de Educação Integral, que pressupõe um conjunto de estratégias para o desenvolvimento pleno do ser humano, a partir da integração e ampliação de tempo, espaços e conteúdos de aprendizagem, dentro e fora da escola. Nesse sentido, reconhece e avalia os conhecimentos adquiridos, tanto na escola, quanto na comunidade e no contexto familiar como condição fundamental para a construção de uma educação integral de qualidade.

\section{OS PROCEDIMENTOS METODOLÓGICOS DA PESQUISA}

A metodologia que direcionou os trabalhos desta pesquisa teve abordagem qualitativa e inclui-se no campo da pesquisa descritiva. Em relação à pesquisa qualitativa, Chizzotti (2006, p.28) destaca que "o termo qualitativo implica uma partilha densa com pessoas, fatos e locais que constituem objetos de pesquisa, para extrair desse convívio os significados visíveis e latentes que somente são perceptíveis a uma atenção sensível". Chizotti (1991) destaca ainda, que ela é importante por promover a imersão do pesquisador nas circunstâncias e no contexto da pesquisa, o mergulho nos sentidos e emoções; o reconhecimento dos atores sociais como sujeitos que produzem conhecimentos e práticas; os resultados, como fruto de um trabalho coletivo, resultante da dinâmica entre pesquisador e pesquisado; a aceitação de todos os fenômenos, como igualmente importantes e preciosos; a frequência e a interrupção, as revelações e os ocultamentos, a continuidade e a ruptura, o significado manifesto e o que permanece oculto.

Os dados foram produzidos empregando-se um questionário contendo três questões abertas, permitindo assim, uma intensidade maior nas respostas e também, maior liberdade ao responderem. As questões tratavam sobre o trabalho com os cadernos de aprendizagem, de forma que as professoras expressassem qual a importância deles, enquanto instrumentos de avaliação e quais os pontos negativos e positivos do uso desses cadernos para o sucesso da alfabetização.

Marconi e Lakatos (2003, p. 201) conceituam questionário como sendo "um instrumento de coleta de dados, constituído por uma série ordenada de perguntas, que devem ser respondidas por escrito e sem a presença do entrevistador". É importante por garantir o anonimato dos entrevistados, permite que as pessoas o respondam no momento em que entenderem mais convenientes; não expõe o entrevistado à influência do pesquisador; obtém respostas mais rápidas e mais precisas; possibilita mais uniformidade na avaliação, em virtude da natureza impessoal do instrumento. 
Foram realizadas observações do cotidiano das salas de aula buscando meio de entender as relações entre o uso dos cadernos de aprendizagem e os resultados conquistados pelos alunos e professores no processo de alfabetização. Gil (1999) destaca que na observação, os fatos são percebidos de forma direta, sem que haja qualquer tipo de intermediação, sendo considerada uma vantagem, em comparação aos demais instrumentos.

O campo da pesquisa foram duas classes de alfabetização do Programa Palavra de Criança, situadas na Unidade Escolar Tia Deca, escola da rede municipal de ensino de Buriti dos Montes (PI). A mesma apresenta bons resultados de trabalhos e seus reflexos tem gerado visibilidade nacional e internacional. Os interlocutores foram duas professoras participantes do programa Palavra de Criança e que fazem uso dos cadernos de aprendizagem propostos.

\section{PRODUÇÃO E DISCUSSÃO DOS DADOS}

Os dados foram avaliados obedecendo a três categorias, como: sentidos de trabalho com cadernos de aprendizagem, importância desses cadernos enquanto instrumentos de avaliação, pontos positivos e negativos do uso de cadernos de aprendizagem. Essa técnica denominada análise de conteúdo de Bardin (1979), a qual se constitui de descrição objetiva e sistemática do conteúdo manifestado nos dados dos interlocutores.

Em relação ao modo como foi trabalhar com os Cadernos de Aprendizagem, as professoras colocam-se intensamente engajadas em utilizá-lo, acreditando que eles favorecem a continuidade do processo de ensino dos alunos. É possível verificar essas concepções em suas falas, quando afirmam:

Trabalhar com os cadernos de aprendizagem foi muito gratificante. Receber um aluno e poder ver algum registro do que ele já consegue, do que ele sabe fazer, produziir nos orienta melhor e com isso nos permite continuar o trabalho formativo das crianças. (Professora A)

Os cadernos orientam bastante nosso trabalho, os cadernos nos permitem fazer reflexões sobre os alunos e isso pode provocar mudanças em nós mesmos professores alfabetizadores, por exemplo e fazer com que os alunos aprendam mais. Quando avaliamos as produções dos cadernos no início do ano é como se não estivéssemos iniciando, mas continuando a ensinar aquela criança. O caderno é muito interessante. (Professora B)

Para as educadoras, que lecionam no ciclo de alfabetização, elas acreditam o uso dos cadernos permitem a realização de um trabalho formativo uma vez que promove a reflexão a partir da realidade do aluno. Analisar os registros dos alunos e dos professores no ano anterior é uma proposta que vem sendo difundida entre elas e vem sendo aprofundado cada vez mais, de 
forma que os alunos são melhor recebidos e sua aprendizagem é respeitada, exatamente no nível em que ele se encontra.

Sobre a importância dos Cadernos, enquanto instrumento de avaliação, as professoras salientam que:

Os cadernos de aprendizagem são instrumentos que nos fortalecem, norteia nossos trabalhos, eles possibilitam que nós professores vejamos a evolucão dos nossos alunos, o que eles sabem, nos permite conhecer que niveis de aprendizagem ele já conquistaram a partir de seus rabiscos, producōes, atividades. Vejo que adotar os cadernos como instrumento de avaliação é acreditar nos alunos, é fazer um trabalho contínuo, é reconbecer que a criança não acaba num ano para recomeşar no outro. A aprendizagem é algo continuo. Os cadernos preveem isso: uma avaliação formativa, mediadora e integral como bem propõe o Palavra de Criança, de onde provem a proposta. (Professora A)

Os cadernos são importantes sim. Nos servem para verificar os percursos já trilhados pelos alunos e assim possamos encaminhar melhor os nossos trabalhos de ensino. Também é bom para mostrar para os alunos as atividades que eles faziam de uma maneira e em outro momento fazem de outro e com certeza melhor. (Professora B)

As falas das interlocutoras evidenciam que os Cadernos, inevitavelmente favorecem uma avaliação formativa, mediadora e integral, uma vez que entende a criança como um ser com aprendizagem contínua. Para as educadoras, os Cadernos têm uma importância significativa para delinear das atividades a serem desenvolvidas com os alunos para e continuar o processo de ensino aprendizagem.

O uso do caderno como instrumento de avaliação reconhece ainda, na visão das professoras, que a criança não é um ser fragmentado que vai passando de professor em professor. Mas que cada ano é uma continuidade do outro e precisam ser reconhecidas as habilidades conquistadas para que haja a continuidade do processo de ensino e de aprendizagem.

Em relação aos pontos positivos e negativos do uso dos Cadernos de Aprendizagem, as professoras relatam o seguinte:

A maneira de como o caderno é proposto, visando uma avaliação formativa, mediadora $e$ integral que vê o aluno como um ser que apresenta aprendizagem continua é um ponto bastante positivo. Além do que, permite a nós professores, conhecer os alunos que estamos recebendo e continuar os mesmos trabalhos durante o ano, para que o próximo professor também conheça o aluno que vai receber e veja o que propomos durante o ano letivo. Como ponto negativo do uso do caderno, vejo que os professores podem avaliar não os alunos, mas as atividades propostas pelo professor e lançar preconceitos sobre os colegas profissionais. Além do que alguns alunos podem conseguir se autoavaliar a partir de suas próprias atividades. Não vejo assim, ponto tão negativos em relação aos cadernos de aprendizagem como instrumentos de avaliação não. (Professora A)

Os pontos positivos em relação ao uso dos Cadernos de Aprendizagem é justamente nas possibilidades de verificar uma situação ou nivel de produção dos alunos. Os cadernos se faz̧em importante à medida que permite aos professores identificarem a partir do que vão iniciar seu trabalbo de ensino sem necessariamente pensar que vão iniciar o processo e aprendizagem dos alunos, mas que vão dar continuidade e essa continuidade precisa acontecer a partir de uma 
avaliação da realidade. Os cadernos figuram essa realidade para o professor. Quanto os pontos negativos, não me considero capaz de dizer nenhum. Trabalbo com essa proposta no programa palavra de criança e a considero muito importante para a continuidade do trabalho e o sucesso dos alunos. (Professor B)

Como todo e qualquer instrumento de avaliação, apresenta vantagens e desvantagens, o uso dos cadernos de aprendizagem também é motivos de discordâncias. De acordo com a professora $\mathrm{A}$, os cadernos são muito importantes, mas podem favorecer a discordância entre os educadores de um ano para o outro, e também, nem todos os alunos sabem realizar sua autoavaliação, mas considera que o método tem mais a contribuir com pontos positivos do que com negativos. Já a professora $\mathrm{B}$, não se sente capaz de afirmar que o método apresenta negatividade em sua execução, pois considera uma alternativa facilitadora e consistente para os educadores ao realizar uma conexão entre os trabalhos realizados pelo professor do ano anterior as novas atividades a serem realizadas para os alunos, de forma que o mesmo tem uma aprendizagem contínua.

Foram realizadas visitas nas salas de aulas pesquisadas e os dados observacionais revelam que o Caderno de Aprendizagem é um instrumento de avaliação no qual os estudantes trabalham com suas dúvidas e possibilidades de avanço, facilitando a prática de uma avaliação formativa e de estudos paralelos, podendo ser uma iniciativa do próprio estudante ou uma prática a ser incorporada pelo professor em seu planejamento.

\section{CONSIDERAÇÕES (IN)CONCLUSIVAS}

O Programa Palavra de Criança contribui com uma proposta de avaliação que visa romper com as tradicionais formas de avaliar, que selecionam e/ou excluem as crianças, fragmentam o seu processo de aprendizagem e o seu ser como aprendiz. A avaliação formativa, mediadora e integral busca a diferença, pois é vista como o melhor caminho para garantir a evolução de todas as crianças, é uma espécie de passo à frente em relação às tradicionais formas de avaliar que só buscam somar, julgar e classificar.

O Caderno de Aprendizagem possibilita o acompanhamento da aprendizagem pelas professoras, que de posse dos registros, podem planejar melhor a sua prática docente, esclarecer aos pais sobre o desempenho de suas crianças, permitindo que eles conheçam e participem do acompanhamento do processo evolutivo de seus filhos e possam também, avaliar seus progressos. Apresenta ainda, as evidências e trajetórias de aprendizagem, incluindo esforços, reflexões, progresso e criatividade durante o processo de aprendizagem para que em conjunto, possam acompanhar o seu progresso. 
Para concluirmos essa discussão, retomamos mais uma vez a história da Professora Marta, uma vez que ela nos possibilita reflexões importantes sobre mudança de concepções, sobre o compromisso docente com a avaliação formativa, mediadora e integral, mas principalmente com o ser humano que existe em cada criança, que por meio de gestos, muitas vezes, agressivos e indiferentes, clamam por um olhar amoroso e comprometido de um professor ou professora. Encerramos com o desejo de que cada docente possa um dia reencontrar e abraçar seus alunos e ouvir deles a frase que disse Víctor a Professora Marta: obrigado por acreditar em mim e me fazer sentir importante, demonstrando-me que posso fazer a diferença.

\section{REFERÊNCIAS}

BARDIN, L. Análise de conteúdo. Lisboa: Edições 70, 1979.

BRASIL. Indagações sobre currículo: currículo e avaliação. Brasília: Ministério da Educação, Secretaria de Educação Básica, 2007.

. Ministério Educação e Cultura. Lei de Diretrizes e Bases da Educação. Disponível em: < http://www.mec.gov.br >. Acesso em: 10 dez. 2013.

Ministério da Educação. Secretaria de Educação Básica. Diretrizes Curriculares

Nacional para a Educação Infantil/ Secretaria de Educação Básica. - Brasília: MEC, SEB, 2010.

Referencial curricular para a educação infantil. Brasília: Secretaria de Educação Funda mental/MEC, SEF, 1998.

CARDOSO, Bruna. Práticas de Linguagem Oral e Escrita na Educação Infantil. São Paulo: Anzol, 2012.

FERNANDES, D. Para uma teoria da avaliação formativa. Revista Portuguesa de Educação. 19(2). (pp. 21-50). 2006. CIEd -Universidade do Minho. Disponível em: < http://www.scielo.oces.mctes.pt/pdf/rpe/v19n2/v19n2a03.pdf >. Acesso em: 20 jul. 2016.

LUCKESI, C. C, Avaliação da aprendizagem na escola: reelaborando conceitos e recriando a prática. Salvador: Malabares Comunicação e Eventos, 2005.

HOFFMANN, Jussara Maria Lerch. Avaliação na Pré-Escola. Porto Alegre: Mediação, 1996.

Avaliar: respeito primeiro, educar depois, 2. Ed. Porto Alegre: Mediação, 2010.

Avaliar para promover: as setas do caminho. Porto Alegre: Mediação, 1995.

Pontos e contrapontos: do pensar ao agir em avaliação. 10. ed. Porto Alegre:

Mediação, 2012.

CHIZOTTI, A. Pesquisa em Ciências Humanas e Sociais. São Paulo: Cortez, 1991. 
Pesquisa qualitativa em ciências humanas e sociais. Petrópolis: Vozes, 2006.

GIL, A. C. Como elaborar projetos de pesquisa. 4. ed. São Paulo: Atlas, 2002.

MARCONI, M. de A.; LAKATOS, E. M. Fundamentos de metodologia científica. 5. ed. São Paulo: Atlas, 2003. 